(2) OPEN ACCESS

${ }^{1}$ Vascular Medicine, Cardiovascular Sciences, University of Amsterdam, Amsterdam UMC Location AMC, Amsterdam, The Netherlands ${ }^{2}$ Experimental Vascular Medicine, Cardiovascular Sciences, University of Amsterdam, Amsterdam UMC Location AMC, Amsterdam, The Netherlands

\section{Correspondence to} Lauré M Fijen;

I.m.fijen@amsterdamumc.nl

Accepted 28 October 2021

Check for updates

(c) BMJ Publishing Group Limited 2021. Re-use permitted under CC BY-NC. No commercial re-use. See rights and permissions. Published by BMJ.

To cite: Fijen $L M$, Grefhorst A, Levels JHM, et al. BMJ Case Rep

2021:14:e246698.

doi:10.1136/bcr-2021-

246698

\title{
Severe acquired hypertriglyceridemia following COVID-19
}

\author{
Lauré M Fijen 이, ${ }^{1}$ Aldo Grefhorst, ${ }^{2}$ Johannes H M Levels, ${ }^{2}$ Danny M Cohn ${ }^{1}$
}

\section{SUMMARY}

Severe hypertriglyceridemia is a major risk factor for acute pancreatitis. In exceptional cases, it is caused by plasma components inhibiting lipoprotein lipase activity. This phenomenon is predominantly associated with autoimmune diseases. Here, we report a case of severe hypertriglyceridemia due to a transient reduction in lipoprotein lipase activity following an episode of COVID-19 in an otherwise healthy 45-year-old woman. The lipoprotein lipase activity of the patient was markedly reduced compared with a healthy control and did recover to $20 \%$ of the healthy control's lipoprotein lipase activity 5 months after the COVID-19 episode. Mixing tests substantiated reduced lipolytic capacity in the presence of the patient's plasma at presentation compared with a homozygous lipoprotein lipasedeficient control, which was no longer present at followup. Western blotting confirmed that the quantity of lipoprotein lipase was not aberrant. Fibrate treatment and a strict hypolipidemic diet improved the patient's symptoms and triglyceride levels.

\section{BACKGROUND}

Severe hypertriglyceridemia (triglyceride concentration $>10 \mathrm{mmol} / \mathrm{L}$ ) is relatively rare and characterised by a markedly increased risk of (potentially lethal) pancreatitis. ${ }^{1}$ The pathogenesis of severe hypertriglyceridemia may reflect a lack of lipoprotein lipase (LPL) functionality due to pathogenic variants in the LPL gene and/or genes associated with LPL function or due to a combination of environmental factors such as alcohol consumption and medication use, ${ }^{2}$ co-morbidities leading to elevated triglycerides such as insulin resistance and hypothyroidism, ${ }^{34}$ and predisposing genetic variants associated with higher triglycerides. ${ }^{5}$ In addition, triglyceride concentrations of approximately $23 \mathrm{mmol} / \mathrm{L}$ have recently been observed in patients with COVID-19. ${ }^{7}$ These patients were treated with tocilizumab or propofol (lipid containing), which have both previously been reported to cause hypertriglyceridemia. ${ }^{89}$ In exceedingly rare cases, hypertriglyceridemia caused by an acquired LPL deficiency syndrome has been described associated with autoimmune diseases. ${ }^{10-13}$ Here, we report the first case of extreme hypertriglyceridemia due to a transient, severe reduction in LPL activity following an episode of COVID-19.

\section{CASE PRESENTATION}

A 45-year-old woman, with stage I hypertension, was diagnosed with COVID-19 after developing mild symptoms that resolved within 2 weeks without hospital admission or newly prescribed medication. One month after the initial onset of these COVID-19 symptoms, the patient experienced nausea, and an aversion for fatty foods, and her symptoms worsened after consumption of small amounts of wine or after copious meals on various occasions. She was referred to our out-patient clinic 3 months after the COVID-19 episode, when her general practitioner had noted markedly elevated triglyceride levels of $44 \mathrm{mmol} / \mathrm{L}$ (reference value 0.6 to $2.2 \mathrm{mmol} / \mathrm{L}$ ). There were no signs or symptoms of acute pancreatitis. Five years earlier, her nonfasting triglyceride concentration was $1.53 \mathrm{mmol} / \mathrm{L}$ at a routine check-up. The patient previously used on average one or two units of alcohol per week and did not use tobacco or oral contraceptives. Her blood pressure was well controlled with lisinopril $40 \mathrm{mg}$ once a day and labetalol $100 \mathrm{mg}$ two times per day. On physical examination, her blood pressure was $132 / 93 \mathrm{~mm} \mathrm{Hg}$. Her weight was $82 \mathrm{~kg}$ with a body mass index of $28.7 \mathrm{~kg} / \mathrm{m}^{2}$. The patient appeared non-critically ill. Physical examination was unremarkable: there was no abdominal tenderness, peripheral oedema, eruptive xanthomas, xanthelasmas or hepatosplenomegaly. Blood and urinary tests (table 1) ruled out conditions causing acute severe hypertriglyceridemia such as hypothyroidism, diabetes mellitus, renal insufficiency, Addison's disease or autoimmune diseases. Abdominal CT showed no signs of pancreatitis. The suspicion of acquired LPL-deficiency was raised.

\section{INVESTIGATIONS}

The patient's plasma lipid concentrations at presentation and 2-month follow-up are listed in table 2. For LPL activity, a mixture of $[9,10-3 \mathrm{H}(\mathrm{N})]$-trioleylglycerol, unlabeled trioleylglycerol and lecithin was emulsified in glycerol.

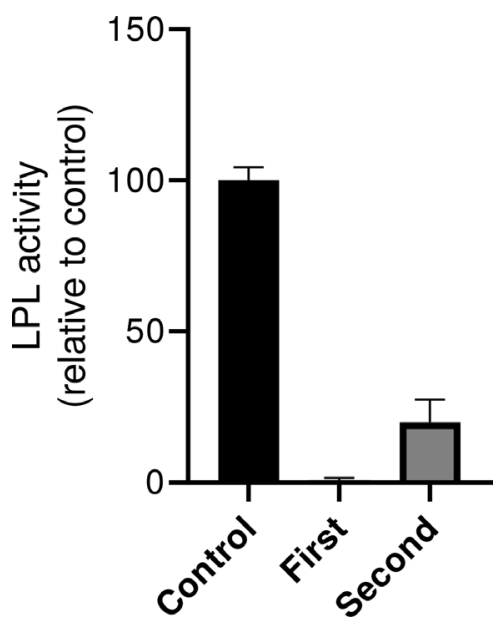

Figure 1 LPL activity of the patient at presentation (first) and 2-month follow-up (second) relative to a healthy volunteer (control). LPL, lipoprotein lipase. 


\begin{tabular}{|c|c|c|}
\hline Test & Value & Normal range \\
\hline $\mathrm{ESR}(\mathrm{mm} / \mathrm{U})$ & 25 & $0-20$ \\
\hline Creatinine $(\mu \mathrm{mol} / \mathrm{L})$ & 87 & $65-95$ \\
\hline EGFR CKD-EPI $\left(\mathrm{mL} / \mathrm{min} / 1.73 \mathrm{~m}^{2}\right)$ & 69 & $>60$ \\
\hline Glucose (mmol/L) & 5.5 & $3.5-6.0$ \\
\hline Lipase (U/L) & 33 & $0-60$ \\
\hline TSH (mU/L) & 2.94 & $0.27-4.20$ \\
\hline Cortisol (nmol/L) & 322 & $250-650$ \\
\hline CRP (mg/L) & 1 & $0-5$ \\
\hline hCG in urine (E/L) & $<2$ & $<2$ \\
\hline
\end{tabular}

CKD-EPI, chronic kidney disease epidemiology collaboration; CRP, C reactive protein; EGFR, estimated glomerular filtration rate; ESR, erythrocyte sedimentation rate; $\mathrm{hCG}$, human chorionic gonadotropin; TSH, thyroid stimulating hormone.;

Non-fasting plasma samples of the patient were incubated with this mixture, BSA-heparin buffer $(18 \%$ BSA, $0.31 \mathrm{mg} / \mathrm{mL}$ heparin and $120 \mathrm{mg} \mathrm{NaCl}$ in $0.3 \mathrm{M}$ Tris buffer, $\mathrm{pH} 8.5$ ) and human serum at $37^{\circ} \mathrm{C}$ in a shaking waterbath for $60 \mathrm{~min}$. The reaction was stopped by adding a mixture of chloroform-methanol-heptane (33:40:27) and a buffer containing $0.1 \mathrm{M} \mathrm{K2CO} 3$ and $0.1 \mathrm{M} \mathrm{H} 3 \mathrm{BO} 3, \mathrm{pH}$ 10.5. The samples were centrifuged at $3000 \mathrm{~g}$ for $5 \mathrm{~min}$ after which the radioactivity in the upper layer was determined. To correct for hepatic lipase activity, the same procedure was performed but with plasma samples incubated in $2 \mathrm{M} \mathrm{NaCl}$. The resultant LPL activity assay (figure 1) showed decreased LPL activity in the patient's plasma compared with plasma of a healthy volunteer.

For LPL mixing tests, non-fasting plasma of the patient and plasma from a control with a homozygous LPL deficiency were mixed in equal proportions with post-heparin plasma of a healthy volunteer and incubated at $37^{\circ} \mathrm{C}$ in a waterbath. Small samples were collected at various time-points for triglyceride (Sopachem) and free glycerol (Sopachem) measurements using a SELECTRA auto-analyser (Sopachem). The free glycerol levels were subtracted from the total triglyceride levels in order to retrieve the net triglyceride concentration. Figure 2 illustrates the absolute triglyceride concentration on addition of $50 \%$ of the patient's plasma to plasma from a healthy volunteer. As a control, the triglyceride concentration of the donor plasma ( $0 \%$ patient's plasma) is shown. Triglyceride lipolysis is inhibited at baseline (figure 2A), but not inhibited at 2-month follow-up (figure 2B). As an extra control, the LPL mixing test was repeated in a patient with congenital LPL deficiency (ie, without an LPL inhibitor). Mixing this patient's plasma with the same healthy donor's plasma resulted in normal triglyceride lipolysis (figure 2C). These LPL mixing tests substantiated that the patient's plasma at presentation contained an LPL-inhibiting

\begin{tabular}{llllll} 
Table 2 & Plasma lipid concentrations at presentation and follow-up \\
\hline Test & Presentation & $\begin{array}{l}\text { Two-week } \\
\text { follow-up }\end{array}$ & $\begin{array}{l}\text { One-month } \\
\text { follow-up }\end{array}$ & $\begin{array}{l}\text { Five-month } \\
\text { follow-up }\end{array}$ & $\begin{array}{l}\text { Normal } \\
\text { range }\end{array}$ \\
\hline $\begin{array}{l}\text { Total } \\
\text { cholesterol } \\
\text { (mmol/L) }\end{array}$ & 15.1 & 5.0 & 4.4 & 4.2 & $<5.0$ \\
$\begin{array}{l}\mathrm{HDL} \\
\text { cholesterol } \\
\text { (mmol/L) }\end{array}$ & 0.8 & 1.6 & 1.8 & 1.7 & $>1.0$ \\
$\begin{array}{l}\text { Non-HDL } \\
\text { cholesterol } \\
\text { (mmol/L) }\end{array}$ & 14.3 & 3.4 & 2.7 & 2.5 & $<3.8$ \\
$\begin{array}{l}\text { LDL } \\
\text { cholesterol } \\
\text { (mmol/L) }\end{array}$ & 1.5 & 1.3 & 1.3 & 1.8 & $<3.0$ \\
$\begin{array}{l}\text { Triglycerides } \\
\text { (mmol/L) }\end{array}$ & 44.0 & 4.7 & 3.1 & 1.4 & $<2.0$ \\
\hline
\end{tabular}

HDL, high density lipoprotein; LDL, low density lipoprotein;

component that impairs the lipolysis activity in the healthy volunteer's plasma.

LPL immunoblotting was performed with a post-heparin plasma sample diluted in reducing sample buffer and denatured at $90^{\circ} \mathrm{C}$ for $10 \mathrm{~min}$. The sample was electrophoresed on a $4 \%-12 \%$ Bis-Tris gel (Invitrogen) and blotted onto a polyvinylidene difluoride membrane (Bio-Rad). Membranes were blocked in 5\% skim milk powder (Sigma-Aldrich) in tris-buffered saline (TBS) with $0.1 \%$ Tween-20 for 1 hour at RT and incubated overnight at $4^{\circ} \mathrm{C}$ with an LPL antibody $(5 \mathrm{D} 2 ; 1: 5000)$ in TBS containing $0.1 \%$ Tween-20\% and 5\% skim milk powder. Next, the membranes were washed and incubated for 1 hour at RT with a horseradish peroxidase-conjugated polyclonal rabbit antigoat antibody (Dako; 1:3000) in TBS containing 0.1\% Tween$20 \%$ and $5 \%$ milk powder. Quantification was performed with the ChemiDoc MP system (Bio-Rad) and SuperSignal West Femto Maximum Sensitivity Substrate (Thermo Scientific). The Western blot (figure 3) showed that the quantity of LPL in the patient's plasma was not aberrant and is thus not causing the reduced LPL activity.

\section{TREATMENT}

The patient was counselled by a dietician to follow a very-low-fat $\operatorname{diet}(\leq 15 \mathrm{~g} /$ day), combined with fibrate treatment (ciprofibrate, $100 \mathrm{mg} /$ day).

\section{OUTCOME AND FOLLOW-UP}

After 2 weeks, triglyceride levels were $4.7 \mathrm{mmol} / \mathrm{L}$ and nausea improved significantly. One month after the initial diagnosis, the strict low-fat diet was loosened. The gastrointestinal symptoms did not recur and non-fasting triglycerides were $3.1 \mathrm{mmol} / \mathrm{L}$.
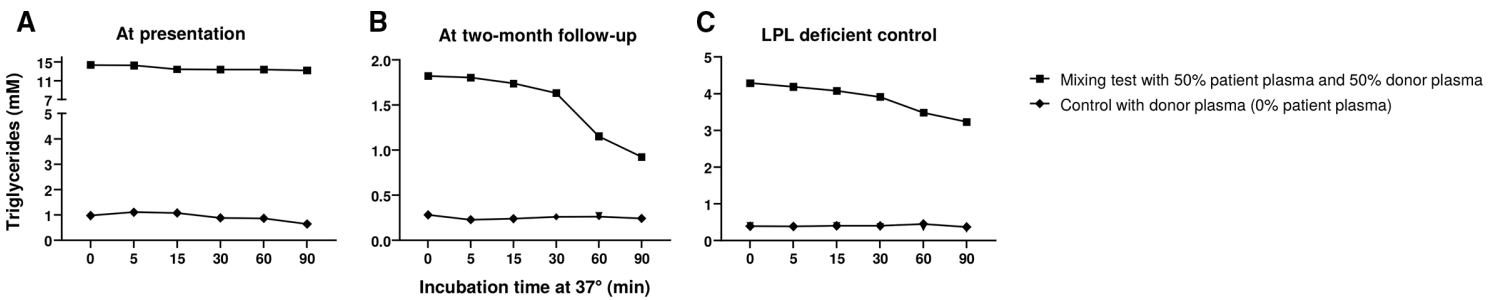

Figure 2 Free glycerol-corrected triglycerides during in vitro plasma mix incubation of plasma from a healthy control and $0 \%$ and $50 \%$ plasma from our case $(A)$ at presentation and (B) at 2-month follow-up compared with (C) plasma from a healthy control mixed with $0 \%$ and $50 \%$ plasma from a patient with congenital homozygous LPL deficiency. LPL, lipoprotein lipase. 

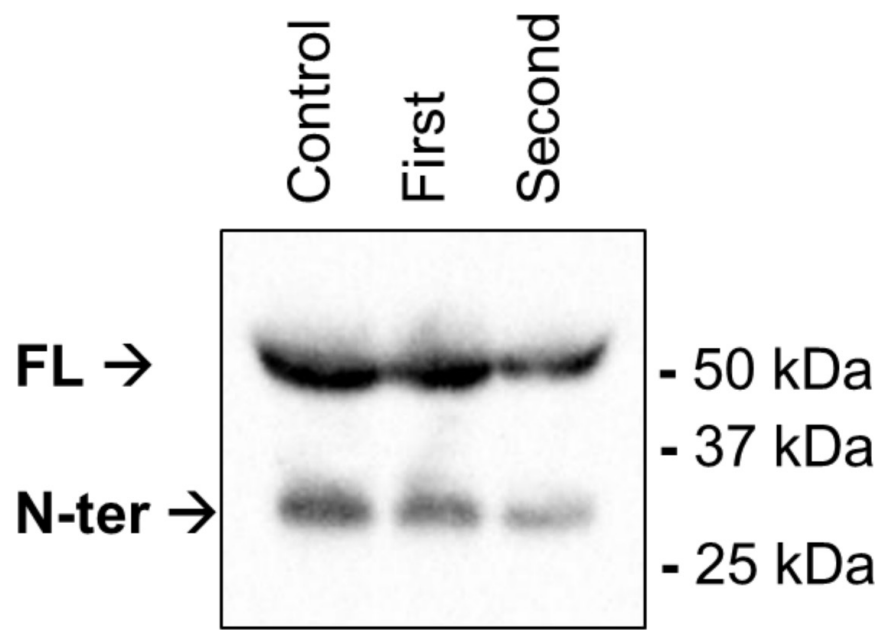

Figure 3 Western blot of lipoprotein lipase quantity of the patient at presentation (first) and 2-month follow-up (second), compared with a healthy volunteer. $\mathrm{FL}$, full-length; $\mathrm{N}$-ter, $\mathrm{N}$-terminal.

Plasma mix studies revealed normalised lipolysis at 2-month follow-up (figure 2), indicating marked lowering of the LPLinhibiting capacity of patient's plasma. The LPL activity assay (figure 1) confirmed an improved LPL activity, although that is still only $20 \%$ of the healthy volunteer's plasma LPL activity.

\section{DISCUSSION}

To our knowledge, this is the first case of severe hypertriglyceridemia following a recent COVID-19 episode. A striking feature of this case were the mild COVID-19 symptoms, which were managed in an outpatient setting. LPL activity assays, LPL mixing studies and LPL western blotting were essential for elucidating the rare cause of the hypertriglyceridemia. Treatment with fibrates and a very-low-fat diet proved to be effective in reducing both the patient's symptoms and triglyceride levels.

Hypertriglyceridemia has previously been reported in patients with COVID-19 but was caused by different factors such as concomitant culprit medication or acute liver failure. ${ }^{7}$ COVID-19 has been shown to be accompanied by excessive production of proinflammatory cytokines. ${ }^{14}$ Previous studies have demonstrated the transient presence of lupus anticoagulant in patients with COVID-19 infection, ${ }^{15}$ which may be associated to the hypercoagulable state seen in COVID-19infected patients. ${ }^{16}$ Analogous, we show a case of acquired LPL inhibition presumably due to excess production of autoantibodies from which the patient recovered 1 month after presentation at our outpatient clinic.

Knowledge of the described rare complication of COVID-19 is crucial for treating physicians in order to recognise the symptoms of acquired LPL deficiency preferably before the patient experiences pancreatitis due to the severe hypertriglyceridemia. The incidence of pancreatitis in patients with LPL deficiency is increased 360 -fold, ${ }^{17}$ with poor prognosis once pancreatitis is present. ${ }^{18}$ If a patient develops severe hypertriglyceridemia following COVID-19, the diagnosis of acquired LPL deficiency should be considered. Mix assays using post-heparin plasma of patients and healthy volunteers are readily available and can be used to identify the presence of an LPL-inhibiting component in the patient's plasma. Vice versa, in patients with acquired severe hypertriglyceridemia, anti-LPL components should be considered when other causes of genetic and secondary hypertriglyceridemia have been excluded, particularly if the patient recently had COVID- 19 .
In our case, conservative treatment using fibrate and extreme dietary fat restriction led to an uncomplicated recovery after a few weeks. In case of severe complications such as pancreatitis, plasmapheresis may be considered ${ }^{19}$ potentially in combination with B-cell reducing interventions. ${ }^{10-13}$

Patient's perspective

I was presumably infected with COVID-19 by a colleague. The diagnosis was made 5 days later. I had a mild disease course with just flu-like symptoms and a maximum temperature of $38.3^{\circ} \mathrm{C}$. About a week later I recovered.

After another few weeks, nausea and excessive saliva production appeared, which was remarkably viscous: almost custard! Also an increasing aversion to fatty foods (especially meat products) with nocturnal vomiting arose, which almost always started between 3 and 5 AM. After I ate a lavish meal on my daughter's birthday, the nausea was so strong that I decided to go to the doctor. A blood test was arranged. Because I had such an aversion to fatty food, I also asked the doctor for a lipid profile. This was determined and the most striking result was triglyceride levels of $44 \mathrm{mmol} / \mathrm{L}$. I was referred to the university hospital where an acquired LPL deficiency was detected with the use of an LPL mixing test. An abdominal CT scan showed that there was no pancreatitis (yet). My complaints decreased quickly after starting a fat-free/very low-fat diet and a ciprofibrate. The triglyceride values also decreased slowly to an acceptable level. After 4 months all complaints had disappeared and the blood results had also normalised after another month.

\section{Learning points}

- Severe hypertriglyceridemia due to a transient inhibitor of lipoprotein lipase activity can occur following an episode of COVID-19.

- Lipoprotein lipase mixing tests are helpful in the diagnostic process of severe hypertriglyceridemia to distinguish between absolute lipoprotein lipase deficiency or an inhibitor of lipoprotein lipase activity.

- Fibrate treatment and extreme dietary fat restriction can quickly improve both clinical symptoms and triglyceride levels.

Twitter Lauré M Fijen @LaureFijen

Acknowledgements We thank Hans Jansen for his contribution to the laboratory analyses, Linda Landman-Booter and Shirin Ibrahim for the collection of plasma samples, and Erik Stroes and Nordin Hanssen for proofreading.

Contributors LMF, AG, JHML and DMC contributed to the planning, conduct and reporting of the work described in the article. DMC identified the case and had the idea for the article. LMF, AG and JHML collected and analysed the data presented. LMF, AG, JHML and DMC interpreted the test results. LMF wrote the first version of the article, and LMF, AG, JHML and DMC revised the article and gave their final approval of the version to be published. LMF is the guarantor.

Funding The authors have not declared a specific grant for this research from any funding agency in the public, commercial or not-for-profit sectors.

Competing interests None declared.

Patient consent for publication Consent obtained directly from patient(s)

Provenance and peer review Not commissioned; externally peer reviewed.

Open access This is an open access article distributed in accordance with the Creative Commons Attribution Non Commercial (CC BY-NC 4.0) license, which permits others to distribute, remix, adapt, build upon this work non-commercially, and license their derivative works on different terms, provided the original work is properly cited and the use is non-commercial. See: http://creativecommons.org/licenses/by-nc/4.0/. 
Case reports provide a valuable learning resource for the scientific community and can indicate areas of interest for future research. They should not be used in isolation to guide treatment choices or public health policy.

\section{ORCID iD}

Lauré M Fijen http://orcid.org/0000-0002-0834-8138

\section{REFERENCES}

1 Brunzell JD, Schrott HG. The interaction of familial and secondary causes of hypertriglyceridemia: role in pancreatitis. J Clin Lipidol 2012;6:409-12.

2 Yuan G, Al-Shali KZ, Hegele RA. Hypertriglyceridemia: its etiology, effects and treatment. CMAJ 2007;176:1113-20.

3 Pavlic M, Valéro R, Duez H, et al. Triglyceride-Rich lipoprotein-associated apolipoprotein C-III production is stimulated by plasma free fatty acids in humans. Arterioscler Thromb Vasc Biol 2008;28:1660-5.

4 Waring AC, Rodondi N, Harrison S, et al. Thyroid function and prevalent and incident metabolic syndrome in older adults: the health, ageing and body composition study. Clin Endocrinol 2012;76:911-8.

5 Moulin P, Dufour R, Averna M, et al. Identification and diagnosis of patients with familial chylomicronaemia syndrome (FCS): Expert panel recommendations and proposal of an "FCS score". Atherosclerosis 2018;275:265-72.

6 Morrison AR, Johnson JM, Ramesh M, et al. Acute hypertriglyceridemia in patients with COVID-19 receiving tocilizumab. J Med Virol 2020;92:1791-2.

7 Thomas CM, Vicent M, Moore S, et al. Treatment of severe hypertriglyceridemia with insulin infusions in severe COVID-19: a case series. J Pharm Pract 2021;89719002110 10473:8971900211010473.
8 Giles JT, Sattar N, Gabriel S, et al. Cardiovascular safety of tocilizumab versus etanercept in rheumatoid arthritis: a randomized controlled trial. Arthritis Rheumatol 2020;72:31-40.

9 Devlin JW, Lau AK, Tanios MA. Propofol-associated hypertriglyceridemia and pancreatitis in the intensive care unit: an analysis of frequency and risk factors. Pharmacotherapy 2005;25:1348-52.

10 Pruneta V, Moulin P, Labrousse F, et al. Characterization of a new case of autoimmune type I hyperlipidemia: Iong-term remission under immunosuppressive therapy. J Clin Endocrinol Metab 1997;82:791-6.

11 Lilley JS, Linton MF, Kelley JC, et al. A case of severe acquired hypertriglyceridemia in a 7-year-old girl. J Clin Lipidol 2017;11:1480-4.

12 Ashraf AP, Beukelman T, Pruneta-Deloche V, et al. Type 1 hyperlipoproteinemia and recurrent acute pancreatitis due to lipoprotein lipase antibody in a young girl with Sjogren's syndrome. J Clin Endocrinol Metab 2011;96:3302-7.

13 Blom DJ, Marais AD. Severe hypertriglyceridemia in a patient with lupus. Am J Med 2005;118:443-4.

14 Ragab D, Salah Eldin H, Taeimah M, et al. The COVID-19 cytokine storm; what we know so far. Front Immunol 2020;11:1446.

15 Harzallah I, Debliquis A, Drénou B. Lupus anticoagulant is frequent in patients with Covid-19. J Thromb Haemost 2020;18:2064-5.

16 Bowles L, Platton S, Yartey N, et al. Lupus anticoagulant and abnormal coagulation tests in patients with Covid-19. N Engl J Med 2020;383:288-90.

17 Gaudet D, de Wal J, Tremblay K, et al. Review of the clinical development of alipogene tiparvovec gene therapy for lipoprotein lipase deficiency. Atheroscler Suppl 2010;11:55-60.

18 Ewald N, Hardt PD, Kloer H-U. Severe hypertriglyceridemia and pancreatitis: presentation and management. Curr Opin Lipidol 2009;20:497-504.

19 Joglekar K, Brannick B, Kadaria D, et al. Therapeutic plasmapheresis for hypertriglyceridemia-associated acute pancreatitis: case series and review of the literature. Ther Adv Endocrinol Metab 2017:8:59-65.

Copyright 2021 BMJ Publishing Group. All rights reserved. For permission to reuse any of this content visit https://www.bmj.com/company/products-services/rights-and-licensing/permissions/ BMJ Case Report Fellows may re-use this article for personal use and teaching without any further permission.

Become a Fellow of BMJ Case Reports today and you can:

- Submit as many cases as you like

- Enjoy fast sympathetic peer review and rapid publication of accepted articles

- Access all the published articles

- Re-use any of the published material for personal use and teaching without further permission

\section{Customer Service}

If you have any further queries about your subscription, please contact our customer services team on +44 (0) 2071111105 or via email at support@bmj.com.

Visit casereports.bmj.com for more articles like this and to become a Fellow 